\title{
De beroepsreglementering van registeraccountants: sloop of verbouwing?
}

\section{Prof. J. H. Blokdijk}

\section{Een voorstel tot vernieuwing}

Enkele maanden geleden werden de leden van het Nederlands Instituut van Registeraccountants (NIvRA) verrast met een 'Rapport van de Commissie Inventarisatie GBR', en met de uitnodiging daarop reacties in te zenden vóór 30 december 1990. 'GBR' staat voor: 'Gedrags- en Beroepsregels Registeraccountants'; de eerdergenoemde, medio 1987 ingestelde commissie had dan ook als taakopdracht te onderzoeken op welke punten het huidige beroepsreglement zou moeten worden gewijzigd of aangevuld. Met de instelling van een dergelijke inventarisatiecommissie volgde het Bestuur van het NIvRA dezelfde procedure als bij de totstandkoming van de GBR in 1973. De Commissie Herziening Beroepsregelen die het ontwerp voor de GBR tot stand bracht, was voórgegaan door een Werkgroep Inventarisatie wijziging GBR, die in 1969 rapport heeft uitgebracht. Door nu opnieuw voor een dergelijke zware procedure te kiezen bracht het NIvRAbestuur tot uitdrukking dat het de GBR aan grondige herziening toe achtte.

De commissie is voortvarend te werk gegaan en heeft onder meer aan de leden en de organen van het NIvRA, alsmede aan andere organisaties, om commentaar op de geldende regels gevraagd. Deze commentaren zijn aan het begin van het rapport samengevat weergegeven.

Daarna geeft de commissie haar 'werkconclusies', die als uitgangspunten voor het verdere rapport gebruikt worden. Dat vervolgt met beschouwingen over kernbegrippen van accountantsethiek, over de definities die de gewenste structuur van de regels moeten ondersteunen, over de gedragsregels voor specifieke functies en over de verkeersregels tussen registeraccountants. Deze beschouwingen worden afgesloten met een samenvatting van conclusies en aanbevelingen, gevolgd door een artikelsgewijs overzicht van de geldende GBR en de daarop voorgestelde wijzigingen.

Toen de commissie haar werkzaamheden vrijwel had beëindigd, verscheen het rapport van de Commissie Advisering Stroomlijning Accountantswetgeving, beter bekend als de 'commissieGeelhoed'. De Commissie Inventarisatie GBR heeft er van afgezien de mogelijke consequenties van 'Geelhoed' geheel in haar rapport te verwerken, doch heeft volstaan met de toevoeging van een laatste hoofdstuk waarin in het kort de betekenis van de mogelijke wijzigingen in de wettelijke regeling voor de commissievoorstellen omtrent de gedragsregels wordt geschetst. Daaruit wordt duidelijk dat een deel van de voorstellen onder de nieuwe wetgeving niet uitvoerbaar zal zijn.

De Commissie heeft een zeer brede studie uitgevoerd en daarbij een grote verscheidenheid aan onderwerpen aangeroerd, hetgeen in het rapport zijn weerslag heeft gevonden. In het navolgende is de behandeling van het rapport beperkt tot hoofdlijnen: de aard, de structuur, de uitgangspunten en de functie van de voorgestelde regeling; daarna zal in het kort op enkele details worden ingegaan, vooral met betrekking tot het

Prof. J. H. Blokdijk, registeraccountant, is lid van de maatschap KPMG Klynveld Kraayenhof \& Co. Hoogleraar Accountantsopleiding aan de Vrije Universiteit,

Amsterdam, Lid van het College voor

Beroepsvraagstukken van het NIvRA. 


\section{MAB}

openbare accountantsberoep. Ten slotte zullen enkele conclusies worden getrokken.

\section{De aard van de regeling: gebod versus verbod}

De commissie toont zich zeer gevoelig voor ontvangen kritiek op het 'kapstokartikel' in de huidige GBR, dat de registeraccountant (RA) oplegt 'zich te onthouden van al hetgeen schadelijk is voor de eer van de stand der registeraccountants'(artikel 5). Deze negatieve formulering zou vervangen moeten worden door een positieve, waarbij de commissie denkt aan een eis tot 'collegialiteit' (p. 6). De commissie acht dit vraagstuk van 'stijl en woordkeuze' terecht van principiële betekenis ( $\S 8.1$, sub 1, p.53).

De keuze tussen een negatieve en een positieve formulering is echter veel méér dan een kwestie van fraaiere stijl en woordkeuze: het is de principiële keuze tussen verbod of gebod, tussen weinig of veel regelen. De commissie roept zelf de reden voor de in 1973 gemaakte keuze voor een verbod in herinnering: de toetsing van de naleving is veel eenvoudiger dan bij een gebod (p. 6). De keuze voor een moeilijker toetsbare oplossing zou gerechtvaardigd zijn indien uit de tuchtrechtspraak zou zijn gebleken dat het huidige artikel 5 leidt tot uitspraken die het rechtsgevoel niet bevredigen, maar daarvan maakt de commissie geen gewag.

De keuze voor geboden brengt de noodzaak met zich mee een groot aantal ethische principes te verwoorden; dit doet de commissie dan ook, en zij verwijst daarbij naar buitenlandse en internationale gedragscodes voor accountants. Er is echter een wezenlijk verschil tussen de GBR en deze uitspraken: de GBR zijn een verordening van publiekrechtelijk lichaam, en hebben dus een 'gewicht' dat boven het NIvRA zelf uitgaat.

In deze tijd, waarin deregulering toch nog altijd op meer bijval mag rekenen dan nieuwe regelgeving, lijken de door de commissie gegeven redenen te zwak om een principieel andere keuze te maken bij de redactie van een kernartikel van de gedragsregels. Bedacht moet ook worden dat de regelgeving door het voorstel vooral wordt verzwaard voor RA's die niet als accountant plegen op te treden. De commissie zit er kennelijk zelf ook een beetje mee: haar samenvatting van deze kwestie beëindigt zij met de cryptische zin: 'Open, positieve principes lijken dan ook om adviezen vanuit de beroepsorganisatie te vragen' (§8.1, sub 1, p.53).

De suggestie om het archaïsche begrip 'de eer van de stand' te vervangen door 'collegialiteit' zou ondersteuning verdienen als deze laatste term niet een wat te knusse klank zou hebben: 'accountants-onder-elkaar'; het mist het naar buiten gerichte dat 'de eer van de stand' wel heeft. Een betere vondst zou zeker welkom zijn.

\section{De structuur van de regeling: functie versus optreden}

De huidige GBR kennen een indeling naar hoofdstukken, waarvan de toepasselijkheid afhangt van het optreden van de RA: al dan niet als (al dan niet openbaar) accountant. De GBR hebben dan ook een concentrische opbouw: eerst bepalingen voor alle RA's, daarna verdere regels voor RA's die optreden als accountant, en tenslotte nadere bepalingen voor RA's die optreden als openbaar accountant. Bij lezing van de GBR wordt de aandacht als het ware vanzelf vernauwd tot de openbare accountant. De commissie wil de gedragsregels inrichten naar functie en dus niet meer naar optreden, met als voordeel dat meer gelijkwaardige aandacht zou worden gegeven aan verschillende categorieën RA's.

Om dit te bereiken voert de commissie het begrip 'professioneel optredende RA' in. Zij definieert dit niet, doch uit haar beschrijvingen kan de volgende omschrijving worden gedistilleerd (pp. 3536):

Een professioneel optredende $R A$ is een $R A$ die werkzaam is op de volgende gebieden:

- het beroepshalve onderzoek naar de getrouwheid van een verantwoording;

- het geven van adviezen op administratieforganisatorisch, organisatorisch en bedriffseconomisch gebied;

- het verzorgen van administraties en/of de daaraan te ontlenen verantwoordingen;

- het verzorgen van belastingaangiften en het geven van fiscale adviezen. 


\section{MAB}

Deze categorie wordt onderverdeeld in de volgende functies (p. 33):

a accountant: het onderzoeken van de getrouwheid van verantwoordingen, alsmede het geven van aan genoemd onderzoek inherente adviezen. Onder de functie valt ook het beoordelen of het opstellen van verantwoordingen en de advisering daaromtrent;

b financieel-administratief functionaris: het voorzien in bestuurlijke informatiebehoeften van een huishouding in de private sfeer of van de overheid, een overheidsdienst of -instelling bij wie hij in dienstbetrekking is, alsmede het verrichten van alle taken welke daarmee verband houden;

c adviseur: het geven van adviezen en het behandelen van aangelegenheden op het gebied van de belastingen alsook op administratief-organisatorisch en bedrijfseconomisch gebied ten behoeve van opdrachtgevers tot wie hij niet in een dienstbetrekking staat.

De functie van accountant is onderverdeeld in:

a1 openbare accountant: zelfstandige uitoefening van de accountantsfunctie ten behoeve van het maatschappelijk verkeer, voor eigen rekening of voor gemeenschappelijke rekening met andere openbare accountants en/of zelfstandige beroepsbeoefenaren dan wel in dienstbetrekking tot een rechtspersoon of een of meer andere openbare accountants, en:

a2 niet-openbare accountant: uitoefening van de accountantsfunctie in dienstbetrekking tot een huishouding in de private sfeer of tot de overheid, een overheidsdienst of -instelling en wel direct of indirect ten behoeve van zijn werkgever of de economische eenheid waartoe deze behoort.

Bij nauwgezette beschouwing blijken deze omschrijvingen nog menige onnauwkeurigheid te bevatten. Zo is een financieel-administratief functionaris ook heel gemakkelijk als niet-openbaar accountant te classificeren; zo zal ook de rechtspersoon waartoe een openbaar accountant in dienstbetrekking kan staan, wel nadere beperkingen moeten kennen. Deze en andere details zijn echter voer voor juristen die de volgende commissie zullen moeten bijstaan.

De overgang van optreden naar functie als basis voor de structuur van het reglement wordt door de commissie in de eerste plaats gemotiveerd met een beroep op de waarschijnlijk allerwegen erkende 'onleesbaarheid' van het huidige artikel 2 GBR. Daarin wordt geregeld wanneer sprake is van het optreden als (al dan niet openbaar) accountant. De commissie meent dat dit artikel zo moeilijk te verstaan is doordat het twee zaken tegelijk tracht te regelen: de verschillende functies en het openbaar maken van accountantsverklaringen (§5.2, p. 32).

De commissie ontveinst hier de ware problematiek. De 'onleesbaarheid' van artikel 2 GBR dateert van 13 december 1979, toen de publiekrechtelijke Orde van NIvRA niet bij machte bleek te doen waar de privaatrechtelijke vereniging NIvA in 1947 wel toe in staat was: het afschaffen van verouderde, in het buitenland ongebruikelijke vormen van beroepsuitoefening; integendeel, deze vormen werden toen gecodificeerd in artikel 2 GBR. Het NIvRA is hier dan ook niet trots op: tekenend is dat het zijn publikatie Pilot 1, bevattende de vertaling in het Engels, Frans en Duits van de tekst van de GBR van 1973, nimmer heeft herdrukt, hoewel de uitgave reeds lang is uitverkocht. Een algehele herziening van de GBR zonder dat over vorenstaand vraagstuk ook maar gerept wordt, is nogal onwezenlijk.

De reden waarom artikel 2 GBR mede over de openbaarmaking van verklaringen spreekt, is dat artikel 2 het optreden van RA's moet regelen, en wel zodanig dat de aard van het optreden herkenbaar is voor gebruikers van accountantsverklaringen. Voor hen is de openbaarmaking van een accountantsverklaring een objectief vaststelbaar feit, zodat ook redelijk duidelijk kan zijn in welke functie de RA optreedt. Door de keuze voor de 'functie' in plaats van het 'optreden' als uitgangspunt van de regelgeving wordt het aspect van de herkenbaarheid geheel verwaarloosd, tot schade aan de externe functie van het reglement (zie ook hoofdstuk 5 van dit artikel). 


\section{MAB}

Het loslaten van het 'optreden' als beslissende factor is de commissie niet gelukt: men voert de 'professioneel optredende RA' ten tonele, en in hoofdstuk 6 , over de gedragsregels voor de specifieke functies, wordt steeds gesproken over 'de als.....optredende RA'.

Ook de concentrische opbouw van de regeling blijkt niet te vermijden: blijkens de (in $\S 8.1$ sub 4 , p. 55) voorgestelde structuur komen er regels voor de professioneel optredende RA, met aanvullende regels voor (individuele) accountants, en daarna voor samenwerkingsverbanden van openbare accountants. De toedeling van de materie over de verschillende hoofdstukken verschilt van de huidige GBR, maar de opbouw blijft concentrisch. Zoals nog nader zal blijken, heeft de commissie de door haar gewraakte overmaat aan aandacht voor de openbare accountant bestreden door de individuele openbare accountant geheel uit het beeld te laten verdwijnen.

Over de aandacht van de commissie zullen ook twee andere categorieën ontevreden zijn: de overheidsaccountants en de branche-accountants, die beiden in de categorie 'niet-openbare accountants' ondergebracht worden. Enige verbazing wekt voorts de mededeling van de commissie dat EDP-auditors en operational auditors ook onder de definitie van 'accountant' vallen, omdat zij 'ook direct of indirect als doelstelling van hun arbeid de getrouwheid van de verantwoording kennen' ( $\$ 5.3$, p. 34; cursivering: JHB). Eerder stelt de commissie terecht dat de omschrijving van de functie 'accountant' noopt tot een definitie van het begrip 'verantwoording', en sluit daarvoor aan bij Richtlijn voor de Accountantscontrole 1.01. In $\$ 5$ van deze Richtlijn wordt evenwel duidelijk gemaakt dat de objecten van onderzoek van EDP-auditors en operational auditors niet als verantwoordingen in de zin van de Richtlijn kunnen worden gekenschetst. De desbetreffende RA's zouden zich waarschijnlijk beter thuisvoelen in de categorie 'adviseurs'.

De commissie is er stellig in geslaagd om minder eenzijdige aandacht aan de openbare accountants te geven. Voor de nu zo duidelijk onderscheiden ander categorieën RA's zijn uiteraard vooral de gevolgen van de toegenomen aandacht van belang.

\section{De uitgangspunten: ethische beginselen}

Zoals eerder gezegd, vereist de overgang van verboden naar geboden de formulering van de vooral ethische - beginselen waarop die geboden stoelen. Daaraan wijdt de commissie een apart hoofdstuk. De conclusies kunnen het best worden weergegeven door de letterlijke weergave van de samenvatting van de commissie $(\$ 4.3 .3$; p. 30):

a Voor alle RA's in hun professioneel handelen zijn kernbegrippen van bedrijfsethiek: objectiviteit, integriteit, deskundigheid, geheimhouding en collegialiteit.

b Voor de controlerende accountant is daarnaast onafhankelijkheid (in feitelijke zin) een essentieel constituerend begrip. Voor de zelfstandige, openbare controlerende accountant omvat dit ook de functionele onafhankelijkheid (geen dienstverband) jegens de gecontroleerde of opdrachtgever. Andere aspecten van onafhankelijkheid zijn in optimaliserende zin te formuleren.

c Voor niet-controlerende functies (bijvoorbeeld Finad) is het begrip 'loyaliteit' mogelijk relevant.

De commissie voegt hieraan toe dat de onder a genoemde kernbegrippen primair economisch zijn te motiveren.

De in het vorige hoofdstuk van dit artikel weergegeven omschrijvingen van diverse categorieën RA's worden in het rapport van de commissie eerst na vorenstaande samenvatting van de conclusies over de ethische beginselen gegeven, maar de lezer herkent de hierin genoemde categorieën: sub a de professioneel optredende RA, sub b de accountant en sub $c$ de financieel-administratief functionaris. Het is belangwekkend na te gaan welke concrete eisen de commissie aan elk van deze categorieën denkt te moeten stellen. Voor de professioneel optredende RA worden de volgende eisen voorzien $(\S 6.2)$ :

a het onbevooroordeeld en integer zijn in zijn fungeren;

b het op peil houden van de voor de functie relevante deskundigheid en het in acht nemen van de grenzen van deze deskundigheid;

c duidelijkheid in optreden en uitingen; 


\section{MAB}

d het in acht nemen van de geheimhoudingsplicht;

e het voldoen aan hoge kwaliteitsnormen.

Terugblikkend naar de eerder weergegeven 'kernbegrippen van bedrijfsethiek voor alle RA's in hun professioneel handelen' lijkt een vertaling van 'collegialiteit' te ontbreken, maar elders heeft de commissie dit begrip als vervanging van 'de eer van de stand' voor alle RA's geïntroduceerd (zie hoofdstuk 2 van dit artikel). Omgekeerd zijn noch 'duidelijkheid in optreden en uitingen' (c), noch 'het voldoen aan hoge kwaliteitsnormen' (e) op de eerdergenoemde 'kernbegrippen van bedrijfsethiek' terug te voeren.

De 'duidelijkheid in optreden en uitingen' moet waarschijnlijk dienen om de eerder gesignaleerde overgang van optreden naar functie als leidend beginsel te compenseren; zonder meer concrete voorschriften valt echter nog moeilijk te zeggen of deze compensatie voldoende zal zijn.

Dat 'het voldoen aan een hoge kwaliteitsnorm' niet terug te voeren is op een van de genoemde kernbegrippen van de bedrijfsethiek wijst op een gebrek in de analyse. Daar 'deskundigheid' al bij een van de andere eisen is genoemd, gaat het hier om 'zorgvuldigheid', in de Angelsaksische accountantswereld bekend als 'due care'. De commissie schuift dit element echter onder 'deskundigheid', hetgeen het betoog wat vertroebelt. Dit geschiedt overigens ook door de merkwaardige kritiek die de commissie op artikel 11 GBR lijkt te hebben. Dit artikel zegt thans dat de RA slechts mededeling omtrent de uitkomst van zijn arbeid doet voor zover zijn deskundigheid en de door hem verrichte werkzaamheden daarvoor een deugdelijke grondslag vormen (cursivering JHB). De commissie meent dat deze tekst de mogelijkheid open laat dat de omvang van de verrichte werkzaamheden onvoldoende zou kunnen zijn, en meent een adequate deugdelijke grondslag te moeten eisen ( $\$ 6.2$, sub e; pp. 38/39); dit lijkt mij echter een pleonasme. De commissie meent dat het huidige artikel 11 beter kan luiden: 'Het werk van de professioneel optredende RA voldoet aan hoge kwaliteitsnormen en bij zijn daarop gebaseerde uitingen neemt hij een grote mate van zorgvuldigheid in acht'. In deze tekst wordt een normatief begrip ('deugdelijk') vervangen door relatieve begrippen ('hoge', 'grote'), hetgeen een verzwakking lijkt.

Voor de als accountant optredende RA bepleit de commissie de volgende gedragsregels:

a De accountant is zich bewust van zijn onpartijdigheid in verband met zijn publieke taak.

b De accountant draagt zorg voor een optimale onafhankelijkheid in zijn optreden.

c De accountant neemt de door het bestuur gepubliceerde Richtlijnen voor de Accountantscontrole in acht.

d Bij het ingaan op een verzoek tot het aanvaarden van een opdracht, dient de accountant inlichtingen te vragen aan de huidige accountant van de desbetreffende huishouding.

e Indien de accountant optreedt in een eenheid met andere accountants of beoefenaren van andere beroepen, dienen maatregelen te worden getroffen die de accountant in staat moeten stellen de medeverantwoordelijkheid te kunnen dragen voor de arbeid van die anderen.

$f$ De accountant doet geen ongevraagde dienstaanbieding.

Zeer opvallend is dat geen onderscheid wordt gemaakt tussen openbare en niet-openbare accountants. De eis van onpartijdigheid wordt gesteld 'in verband met zijn publieke taak', maar dat kan niet de motivering zijn voor niet-openbare accountants.

Het gebrek aan onderscheid tussen niet-openbare en openbare accountants is nog verbazingwekkender bij de eis van onafhankelijkheid. In eerdere beschouwingen (\$4.3.2) wordt onderscheid gemaakt tussen de functionele onafhankelijkheid, de afwezigheid van een dienstverband of soortgelijke overeenkomst, en andere vormen van onafhankelijkheid, die minder of niet objectief waarneembaar zijn. Deze laatste vormen, die zijn samen te vatten als 'independence in mind', zijn vereist voor alle accountants: daarenboven wordt de functionele onafhankelijkheid, de 'independence in appearance', van openbare accountants geëist. Dit is een helder onderscheid, dat in de huidige GBR is terug te vinden, maar door de 


\section{MAB}

commissie in haar voorstellen zo is verdoezeld dat de onafhankelijkheid voor openbare accountants niet meer als afzonderlijke eis naar voren komt.

Het verlangen tegemoet te komen aan de zo gewenste pluriformiteit van het ledenbestand van het NIvRA lijkt de commissie te hebben verleid tot een zodanige uniformiteit van regelgeving dat zeer belangrijke verschillen in de posities van accountants niet meer herkenbaar zijn. De openbare accountants worden ook verder zo veel mogelijk uit de voorgestelde regelgeving geweerd; de aanvullende regels voor openbare accountants hebben slechts betrekking op de vormen van toegelaten beroepsuitoefening en op samenwerkingsverbanden. Deze regels betreffen het optreden in collectiviteiten; de individuele openbare accountant komt niet afzonderlijk aan de orde.

Het komt mij voor dat degenen die enige moeite hebben de ingewikkelde en verspreide beschouwingen over kernbegrippen van bedrijfsethiek te volgen, nauwelijks een verwijt is te maken.

Zo wordt het begrip 'objectiviteit' in verband gebracht met 'onbevooroordeeld' en met 'onpartijdig' (\$4.3.1, p. 26). Onbevooroordeeldheid wordt als eis gesteld aan alle professioneel optredende RA's (§6.2.a, p. 36), waarbij wordt opgemerkt dat naast dit begrip het begrip 'onpartijdigheid' staat. Onpartijdigheid wordt geëist van alle RA's die de accountantsfunctie vervullen (\$6.3.a, p. 40), zoals gezegd: 'in verband met hun publieke taak'. Ten aanzien van openbare accountants merkt de commissie op dat zeker niet kan worden volstaan met onafhankelijkheid als 'geesteshouding', en dat dit belangrijke aspect reeds voldoende begrepen is in de 'onpartijdigheid' (\$6.3.b, p. 41). Waarom het begrip 'onafhankelijkheid' dan niet gereserveerd kan blijven voor de functionele onafhankelijkheid, zoals in de huidige GBR, maakt de commissie niet duidelijk.

Het begrip 'objectiviteit', dat tot dusverre niet in de GBR voorkomt, is al eerder geïntroduceerd in het ontwerp voor Richtlijn voor de Accountantscontrole 2.02, 'Eisen ten aanzien van de accountant'. Op grond van ontvangen commentaren is 'objectiviteit' in de definitieve richtlijn vervangen door 'onpartijdigheid', een begrip dat in de GBR wel een plaats heeft.

Voor de als financieel-administratief functionaris optredende RA stelt de commissie voor uitsluitend de regels voor de professioneel optredende RA van toepassing te verklaren. De commissie heeft nog overwogen een eis tot 'loyaliteit' voor te stellen, maar heeft besloten daarvan voorhands af te zien, zo lang de gedragsregels voor de Registercontrollers nog niet bekend zijn. De lastige vraag is dan ook: loyaal tegenover wie? De commissie stelt héél voorzichtig: wel tegenover de werkgevende organisatie $(\$ 4.3 .2$, p. 30$)$, niet tegenover de superieuren $(\$ 6.5$, p. 49$)$. Dat dit vraagstuk even terzijde is geschoven, is begrijpelijk.

De als adviseur in het vrije beroep optredende RA wordt weliswaar niet genoemd in de eerder weergegeven samenvatting van de commissie over de toepasselijke ethische beginselen (\$4.3.3, p.30), maar de commissie komt ook voor deze categorie met een voorstel voor gedrags- en beroepsregels (\$6.6; pp. 49/50):

a De adviseur is onafhankelijk van zijn opdrachtgever en van degene wiens aangelegenheden hij behandelt.

b De adviseur oefent zijn functie zelfstandig uit, dan wel in dienstbetrekking tot een rechtspersoon, indien en zolang wordt voldaan aan door het bestuur te stellen Algemene Voorwaarden.

c De adviseur is gehouden zorg te dragen voor een zodanige registratie van de verrichte werkzaamheden, dat op aanvaardbare wijze een goed beeld van de uitvoering kan worden gevormd. Hij is gehouden deze registratie tien jaar te bewaren.

d Het optreden van de adviseur in dienstbetrekking tast de eigen vaktechnische verantwoordelijkheid niet aan.

Ten slotte wordt de eis van medeverantwoordelijkheid, die voor openbare accountants geldt, ook aan adviseurs gesteld (zie hoofdstuk 6 van dit artikel).

Over gebrek aan aandacht van de zijde van de 


\section{MAB}

commissie behoeven de adviseurs zich stellig niet te beklagen. Tal van eisen, die tot dusverre slechts voor als (openbaar) accountant optredende RA's golden (en nu voor deze categorieën niet eens meer worden genoemd), worden nu opgelegd aan adviseurs die tevens uit dien hoofde al vaak lid zijn van andere beroepsorganisaties!

De keuze voor geboden in plaats van verboden, en voor de functie in plaats van het optreden, leidt dus tot beduidend meer regels voor RA's die niet als accountant plegen op te treden. De doelstelling van de commissie om minder eenzijdige aandacht aan openbare accountants te geven, wordt hiermee bereikt. De vraag is of de tot dusverre verwaarloosd geachte groepen de extra aandacht in extra regelgeving vertaald willen zien, is echter nog niet beantwoord.

Al met al valt een zeker gebrek aan evenwichtigheid in de voorstellen van de commissie te ontwaren. Bedacht moet echter worden dat regelgeving voor een hybridisch instituut als het NIvRA zeer gecompliceerd is. Voor vele leden is het primaire belang gelegen in de deskundigheidsaanduiding 'registeraccountant', waarvoor zij na jarenlange studie een diploma hebben verworven, dat echter slechts recht geeft op het gebruik van de titel indien en zolang men lid is van een vereniging. Dit is een uiterst ongebruikelijke figuur in de academische wereld. De publiekrechtelijk beschermde titel geeft echter nog altijd méér prestige dan de aanduiding van het lidmaatschap van allerlei privaatrechtelijke beroepsverenigingen, hetgeen met zich mee brengt dat menig lid van het NIvRA zijn jaarlijkse contributie beschouwt als titelhuur. Tussen deze categorie en degenen die de accountantsfunctie vervullen ligt een grote scala van groepen met sterk uiteenlopende betrokkenheid. Om het prestige van de titel hoog te houden (en om enkele andere, veel betere redenen) zijn gedragsregels noodzakelijk; de vraag is: voor wie, in welke mate? De commissie heeft voor de dosering het criterium 'aandacht' gehanteerd; dat lijkt tot onevenwichtigheid te leiden.

\section{De functie van de regeling: ook extern?}

In de toelichting op één van haar eerste werkcon- clusies stelt de commissie dat de GBR ook een externe functie hebben: 'het publiek duidelijk maken aan welke spelregels accountants zich willen en moeten houden' (\$3.2, p. 15). Dit houdt echter volgens de commissie in 'dat alle vaktechnische regelgeving (zoals de regels met betrekking tot de verklaring) geen plaats meer dient te krijgen in de GBR', behoudens enkele delegatieartikelen.

De conclusie van de commissie volgt echter in genen dele uit de stelling. De accountantsverklaring is voorts het slechtste voorbeeld dat de commissie had kunnen kiezen: de verklaring is het instrument waarmee de accountant in het publiek treedt! Dus als accountants spelregels rondom de verklaring hebben, moeten die het publiek duidelijk gemaakt worden. In het kader van de herziening van het stelsel van accountantsverklaringen door het NIvRA heb ik aan dit vraagstuk eerder in dit blad een meer uitgebreide uiteenzetting mogen wijden (Blokdijk, 1989; pp. 397-398).

De gedachten van de commissie waren wel in overeenstemming met de ideeën van het bestuur dat, in het kader van de zojuist genoemde herziening van het verklaringenstelsel, aan de leden het voorstel had voorgelegd de artikelen omtrent de accountantsverklaring uit de huidige GBR te lichten en te vervangen door één bepaling, luidende: 'Het bestuur stelt nadere regelen vast met betrekking tot de bewoording van verklaringen'. Blijkens een brief dd. 1 mei 1990 van het bestuur aan alle leden stuitte dit voorstel op massale weerstand. Naar verwachting zal de voorstellen van de commissie op dit punt een zelfde lot beschoren zijn.

In het kader van de externe functie van de gedragsregels is het a fortiori noodzakelijk de bepalingen omtrent de openbaarmaking van accountantsverklaringen te handhaven: als iéts het publiek raakt, is het wel de publikatie, de openbaarmaking. Hieruit volgt dat ook de definities van 'verklaring' en van 'openbaarmaking' in art 1 GBR gehandhaafd moeten blijven, en wel om de reikwijdte van de spelregels hieromtrent vast te leggen.

Overigens wenst de commissie wel een definitie van 'verklaring' in de regelen op te nemen, maar 


\section{MAB}

geeft hiervoor een geheel andere reden dan de vorenstaande (§6.3; p.40). De commissie lijkt het etiket waarmee uitingen van accountants worden opgesierd te willen definiëren. De definitie van 'verklaring' in de huidige GBR is echter niet bedoeld als voorlichting, maar als wetstechnisch element in de opbouw van het reglement.

Uit het vorenstaande is af te leiden dat de commissie weinig oog heeft gehad voor de externe betekenis van het beroepsreglement. Dat blijkt ook uit de accentverschuiving bij de structurering van het reglement: in plaats van de herkenbaarheid van het optreden staat nu de functie centraal. Ook de verdwijning van de individuele openbare accountant uit de regeling wijst sterk in deze richting. Deze blinde vlek in de aandacht van de commissie blijkt ten slotte ook bij de bespreking van de bestaande bepalingen in de GBR die tot de 'verkeersregels', de regels voor het onderlinge verkeer tussen registeraccountants kunnen worden gerekend.

De commissie doet geen principiële uitspraak over het wel of niet opnemen van dergelijke regels in de GBR. Verschillende visies zijn denkbaar: zo zou men het standpunt kunnen huldigen dat in de GBR geen regels thuishoren die noch het publiek, noch de cliënten van de accountants raken. Dat zou dan betekenen dat bijvoorbeeld de regeling van het collegiaal overleg bij het overgaan van opdrachten (artikel $29 \mathrm{GBR}$ ), in het reglement zou blijven staan, maar de bepalingen over het gebruik van de verklaringen van andere accountants en van andere deskundigen (artikel 15 en 16 GBR) niet. Hierover kan uiteraard ook anders gedacht worden, maar in het rapport komt dit vraagstuk in het geheel niet ter sprake.

De principiële vraag over de functie van de publiekrechtelijke verordening verdient nadere studie, alvorens tot een grondige herziening hiervan wordt overgegaan.

\section{Openbare accountants: enkele bijzonderheden}

Ten aanzien van de openbare accountant beperkt de commissie zich, zoals gezegd, tot de vormen van beroepsuitoefening en de samenwerkingsverbanden waarin openbare accountants werkzaam kunnen zijn. In dat kader wordt veel aandacht besteed aan de medeverantwoordelijkheid en de wijze waarop deze kan worden gedragen. Ten opzichte van de huidige bepalingen lijken de voorstellen enerzijds een verruiming en anderzijds een beperking in te houden.

De verruiming vloeit voort uit het standpunt van de commissie dat medeverantwoordelijkheid ontstaat indien uit het optreden van het samenwerkingsverband naar buiten blijkt dat een gemeenschappelijke marktbenadering, een gemeenschappelijk kwaliteitsniveau en een gemeenschappelijke filosofie ten aanzien van de dienstverlening aan opdrachtgevers wordt nagestreefd ( $\$ 6.4$ sub b; p. 46). Tot dusverre is de gemeenschappelijke naam het criterium voor medeverantwoordelijkheid (artikel 24, lid 3 GBR); mede hierom bepaalt het reglement in artikel 3: 'Met de naam waaronder een registeraccountant optreedt, wordt gelijkgesteld elke zodanig daarop gelijkende naam dat verwarring te duchten valt'. Hierdoor was enige 'jurisprudentie' ontstaan over de vraag wanneer sprake was van een 'ondubbelzinnig onderscheidende naam'; dit was van betekenis voor de afgrenzing van de (mede)verantwoordelijkheid van andere activiteiten dan accountancy. De commissie wil hieraan een einde maken, en geeft daardoor blijk van een goed oog voor de marktontwikkelingen.

De beperking ten opzichte van de huidige regeling is gelegen in de lichtere eisen die de medeverantwoordelijkheid met zich mee lijkt te brengen. Moest het tot dusverre in zekere mate mogelijk zijn de kwaliteit van elkaars werkzaamheden over en weer te beoordelen, thans acht de commissie het voldoende indien de binnen het samenwerkingsverband werkzame beoefenaren van andere beroepen onderling de kwaliteit van elkaars werkzaamheden bewaken, 'voor zover het beoefenaren betreft die zijn ingeschreven als lid van nader door het bestuur aan te wijzen toonaangevende beroepsorganisaties' ( $\$ 6.3$ sub e; $p$. 44).

Een aanverwant onderwerp dat de commissie met nadruk ter sprake brengt, is het collisiege- 


\section{MAB}

vaar. 'Dit thema', zo stelt de commissie in een van haar preliminaire werkconclusies, 'is enerzijds vitaal voor het vertrouwen in de objectiviteit en onafhankelijkheid van de controlerende functie, en anderzijds ook internationaal, waaronder bij de Europese Commissie, nadrukkelijk in discussie. Up-to-date regelgeving zal hierop moeten inspelen.' (§3.8, p. 16).

Ferme taal, al is niet erg duidelijk waarom sprake is van een tegenstelling ('enerzijds/anderzijds'). Helaas blijft het daar vrijwel bij: de commissie lijkt het probleem beperkt te zien tot de samenloop van functies, in de zin van het huidige artikel 25 GBR; zij uit geen enkele concrete gedachte over de regels die zouden kunnen dienen ter vermindering van het collisiegevaar.

\section{Conclusies}

Hoewel in het voorgaande vele belangwekkende en zelfs belangrijke elementen uit het rapport van de commissie onbesproken zijn gebleven, zal duidelijk zijn geworden dat de Commissie Inventarisatie GBR voorstelt de GBR te slopen en geheel te herbouwen. Is dat nodig?

Het schetsontwerp voor de nieuwbouw roept op zijn minst enige kritiek op:

- de overgang van verboden naar geboden is zwak gefundeerd;

- het meest principiële probleem in de huidige GBR blijft onbehandeld;

- de overgang van optreden naar functie als onderscheidend criterium houdt onvoldoende rekening met de externe functie van de beroepsreglementering;

- de ethische beginselen zijn niet helder omschreven;

- de voorgestelde regeling legt veel zwaardere verplichtingen op aan niet als accountant optredende RA's, met name aan in vrij beroep werkzame adviseurs en aan financieel-administratieve functionarissen;

- de voorgestelde verwijdering van de bepalingen omtrent de (openbaarmaking van de) verklaring uit het reglement houdt onvoldoende rekening met de externe functie daarvan;

- de individuele openbare accountant is (vrijwel) onzichtbaar.
Dit laatste is in wezen onaanvaardbaar. Gelukkig heeft het rapport van de Commissie Advisering Stroomlijning Accountantswetgeving nog weer eens duidelijk gemaakt dat het NIvRA een publiekrechtelijke organisatie is uitsluitend omdat de (wettelijke) controle van jaarrekeningen, de taak van de openbaar accountant, publiekrechtelijk geregeld moet worden. Daartoe voldoen de huidige GBR veel beter dan het voorstel van de commissie.

Daarom is sloop prematuur; het is ook nog geheel onduidelijk wie met de herbouw belast zou worden en voor wie het bouwwerk opgetrokken zal worden. Een stevige verbouwing kan evenwel na zo'n twintig jaar geen kwaad. De commissie heeft ook hiervoor stof aangedragen, maar deze dient besproken te worden vanuit andere uitgangspunten dan die welke de commissie heeft gehanteerd. Daarom is het zinvol eerst overeenstemming over de uitgangspunten te verkrijgen. Zoals gezegd, hebben de leden van het NIvRA tot 30 december 1990 de tijd om hierop invloed uit te oefenen.

\section{Literatuur}

Nederlands Instituut van Registeraccountants (NIvRA): Gedragsen Beroepsregels Registeraccountants, 1973, laatstelijk gewijzigd 1987 (NlvRA, opgenomen in RADAR 4/GBR 1)

NlvRA, Richtlijn 1.01, Verantwoordingen en andere objecten van accountantsonderzoek, december 1987 (opgenomen in RADAR Richtlijnen voor de Accountantscontrole RC 1.01, NIVRA)

NivRA, Rules of Conduct en Professional Practice of Registeraccountants/Le Code des Devoirs Professionels des Registeraccountants/Die Verhaltens- und Berufsregeln für Registeraccountants (als gepubliceerd in de Nederlandse Staatscourant van 5 december 1973). Pilot (Netherlands) 1 , NIvRA.

NIvRA, Ontwerp-Richtlijn 2.02, Eisen ten aanzien van de accountant, juli 1988 (opgenomen in RADAR Richtlijnen voor de accountantscontrole Rc 2.02, NIvRA)

NIvRA, Richtlijn 2.02, Eisen ten aanzien van de accountant, maart 1990 (opgenomen in RADAR Richtlijnen voor de accountantscontrole RC 2.02 NIvRA).

NIvRA, Ontwerp ter discussie 25: Rapport van de Commissie Inventarisatie GBR. NIvRA, 1990.

Commissie Advisering Stroomlijning Accountantswetgeving Rapport. Ministerie van Economische Zaken, 1990.

Blokdijk, J. H., Het stelsel van accountantsverklaringen herzien?, MAB, oktober 1989. 